\title{
0 princípio da participação social na gestão de políticas públicas locais: uma análise de experiências latino-americanas e européias*
}

\author{
Carlos R. S. Milani**
}

SumÁrio: 1 . Introdução; 2 . A construção do modelo de análise: as duas óticas principais; 3. Experiências de participação cidadã na América Latina e na Europa ocidental: renovação das políticas públicas locais?; 4. Riscos e limites da participação social na formulação de políticas públicas locais; 5. Conclusão: da manipulação política do princípio participativo à construção de ações públicas locais.

Summary: 1 . Introduction; 2 . The construction of the analytical model: two main views; 3. Experiences of citizen participation in Latin America and Western Europe: renovation of local public policy?; 4. Risks and limits of social participation in the formulation of local public policy; 5 . Conclusion: from the political manipulation of the participatory foundation to the construction of local public actions.

Palavras-chave: políticas públicas; participação; América Latina; Europa; análise comparativa.

KEY WoRDs: public policies; social participation; local public actions; Latin America; Western Europe.

\footnotetext{
* Artigo recebido em out. 2006 e aceito em dez. 2007.

** Doutor em socioeconomia do desenvolvimento pela Escola de Altos Estudos em Ciências Sociais (Paris), professor no Programa de Pós-Graduação em Administração da Universidade Federal da Bahia (UFBA), coordenador do Laboratório de Análise Política Mundial (Labmundo). Implementa, atualmente, o projeto Novas Expressões da Contestação Internacional: Organizações, Redes e Movimentos, com financiamento da Fundação de Apoio à Pesquisa do Estado da Bahia (Fapesb). Professor convidado em várias universidades (Instituto de Estudos Políticos de Paris, Universidade Federal do Rio Grande do Sul, Universidade de Montreal, Universidade de Colima). Foi funcionário da Unesco (Setor de Ciências Sociais e Humanas), entre 1995 e 2002. Endereço: Rua Raul Drumond, 260, ap. 601, Barra - CEP 40130-150, Salvador, BA. E-mail: cmilani@ufba.br.
} 
Este artigo parte de um pressuposto básico: a participação social tornou-se, nos anos 1990, um dos princípios organizativos, aclamado por agências nacionais e internacionais, dos processos de formulação de políticas públicas e de deliberação democrática em escala local. Fomentar a participação dos diferentes atores políticos e criar uma rede que informe, elabore, implemente e avalie as políticas públicas são, hoje, peças essenciais nos discursos de qualquer política pública (auto) considerada progressista. Os anos 1990 foram marcados pela institucionalização da consulta da "sociedade civil organizada" nos processos de formulação de políticas públicas locais. No entanto, os instrumentos participativos devem ser questionados sob, pelo menos, duas óticas críticas principais: quem participa e que desigualdades subsistem na participação? Como se dá o processo de construção do interesse coletivo no âmbito dos dispositivos de participação? Este artigo analisa, a partir de pesquisas realizadas sobre 10 experiências de participação na América Latina (Argentina, Brasil, Costa Rica e República Dominicana) e na Europa (Alemanha, Espanha, França e Itália), em que medida elas representam inovações nos modos de formular, implementar e monitorar políticas públicas locais.

The principle of social participation in the management of local public policies: an analysis of Latin American and European experiments

This article is based on the key argument, praised by national and international agencies, that social participation has become, in the 1990s, one of the main organizational tenets in policy-making and democratic deliberation at the local level. Stimulating the participation of different political actors and creating a political network that informs, elaborates, implements, and evaluates public policies currently constitute an essential part in discourses of self-proclaimed progressive policy-makers. The nineties have been characterized by the institutionalization of consulting "organized civil society" in the processes of defining local public policy. Participation has become a criterium of good local government. Nonetheless, participatory mechanisms must respond to at least two main critical challenges: first, who participates and what inequalities remain within participation? Second, how is collective interest built within participatory mechanisms? This article analyzes, based on research undertaken in 10 experiments in Latin America (Argentina, Brazil, Costa Rica, and the Dominican Republic) and Europe (France, Germany, Italy, and Spain), how they represent innovations in the formulation, implementation, and monitoring of local public policies.

\section{Introdução}

Logo após o início do processo de organização da administração pública no século XIX, dando origem à burocracia moderna, buscou-se resolver o seguinte problema: se não for possível confiar nos representantes políticos, como controlar a burocracia? A resposta passou por estratégias de supervisão, controle e auditoria, consideradas por estudiosos e administradores marcas centrais de 
uma boa administração. Mais de um século se passou, e hoje, volta uma questão semelhante, porém mais complexa: se houver desconfiança em relação aos atos dos representantes políticos e sendo a burocracia ineficiente e pouco transparente aos cidadãos, o que fazer para não comprometer as instituições políticas democráticas e assegurar a efetividade da gestão pública? Desde meados dos anos 1980, as respostas ao dilema "necessidade de políticas públicas efetivas versus garantia de controles democráticos" têm sido múltiplas, dependendo sempre de contextos históricos distintos, visto que a evolução das burocracias nacionais conheceu variações importantes.

No entanto, os modelos construídos para enfrentar tal dilema tendem a incluir, por exemplo, estratégias de descentralização, a adoção de mecanismos de responsabilização dos gestores (responsiveness e accountability), a gestão pública por resultados, o incremento do controle social, além de dispositivos de participação social que visam chamar cidadãos e organizações cívicas para atuarem como atores políticos da gestão pública. Como lembram Bresser-Pereira e Spink (1998), a crise do modelo burocrático de administração pública evidencia com maior centralidade a crise do Estado (como corolário de uma crise econômica) que não logra atender às demandas geradas pela população de forma satisfatória; diante da crise, afirmam que o aparato do Estado deveria primar pela eficiência, eficácia e efetividade das ações, avaliando os processos e resultados de modo a possibilitar a reorientação estratégica da administração pública de forma tempestiva.

Ora, a crise do Estado e a conseqüente necessidade de reforma revelam igualmente limites dos próprios modelos poliárquicos conhecidos na América Latina e na Europa. As poliarquias das sociedades latino-americanas e européias apresentam profunda variação em termos de cultura política, confiança nas instituições, respeito às normas sociais, construção da cidadania e o que Robert Dahl (2001) chamou de "entendimento esclarecido" dos cidadãos. Portanto, pode-se afirmar que o processo de transformação por que passam tais sociedades políticas remete-nos, de fato, a uma dupla crise de governança e governabilidade: de um lado, a crise de governabilidade refere-se à capacidade de formulação, gestão, implementação e articulação das políticas públicas; do outro, a passagem da lógica de governo a uma dinâmica de governança associa-se à legitimidade do Estado enquanto ator e arena política do processo decisório.

Desde o início dos anos 1990, no bojo desse processo de reforma da administração pública na América Latina e alhures, a participação social vem sendo construída como um dos princípios organizativos centrais, declarado e repetido em foros regionais e internacionais, dos processos de deliberação 
democrática no âmbito local. Fazer participar os cidadãos e as organizações da sociedade civil (OSC) no processo de formulação de políticas públicas foi transformado em modelo da gestão pública local contemporânea. A participação social, também conhecida como dos cidadãos, popular, democrática, comunitária, entre os muitos termos atualmente utilizados para referir-se à prática de inclusão dos cidadãos e das OSCs no processo decisório de algumas políticas públicas, foi erigida em princípio político-administrativo. Fomentar a participação dos diferentes atores sociais em sentido abrangente e criar uma rede que informe, elabore, implemente e avalie as decisões políticas tornou-se o paradigma de inúmeros projetos de desenvolvimento local (auto) qualificados de inovadores e de políticas públicas locais (auto) consideradas progressistas.

As origens do discurso sobre a participação social são múltiplas: encontram-se referências (e elogios) à necessidade do uso de ferramentas participativas nos manuais das agências internacionais de cooperação para o desenvolvimento, no âmbito dos programas de reforma do Estado e das políticas de descentralização, mas também na prática de alguns governos locais que afirmam promover, graças à participação dos cidadãos, estratégias de inovação e, em alguns casos, de radicalização da democracia local. A participação é reivindicação histórica de alguns movimentos sociais, por exemplo os relacionados à pauta dos trabalhadores rurais sem terra, à gestão de políticas urbanas ou à educação popular. Além disso, o tema encontra-se bastante presente no âmbito acadêmico e intelectual: como lembram Ziccardi (2004) e Paddison (1999), a participação social é apresentada pelos intelectuais da nova direita como resposta necessária aos impactos nocivos do Estado-providência na construção de uma cidadania ativa; outros cientistas políticos e sociólogos vêm trabalhando com a hipótese do (re)surgimento da democracia participativa baseada em diferentes formas de delegação da representação política (Avritzer, 2003; Bevort 2002; Blondiaux e Sintomer, 2002; Manin, 2002; Blatrix, 2002; Teixeira, 2003; Ziccardi, 2004). Com base em fontes diversas, constrói-se o "princípio participativo", apoiado por atores tão diversos quanto o Banco Mundial, a OCDE, a União Européia, as Nações Unidas, muitas organizações não-governamentais e integrantes do Fórum Social Mundial (Rojo, Milani e Arturi, 2004; Milani e Keraghel, 2005). É evidente que daí decorrem questionamentos críticos acerca do significado e do fundamento da participação social nos diferentes contextos.

Empiricamente e no plano local, os anos 1990 corresponderam à institucionalização da consulta da população em geral, de associações, dos sindicatos, dos experts e de segmentos empresariais no processo de formulação de projetos de desenvolvimento e de políticas públicas. Como ressalta Draibe 
(2002) ao analisar o caso brasileiro, as políticas assistenciais e de combate à pobreza, por exemplo, conheceram, do ponto de vista de sua armação institucional, dois eixos importantes de mudanças: a descentralização do poder decisório e de recursos, bem como a ampliação e a institucionalização da participação. Na Europa e na América Latina, esse movimento vem tendo como conseqüências, inter alia, a legitimação da voz política e o desenvolvimento da expertise de muitos atores não-governamentais.

No entanto, após período de expansão (entre meados dos anos 1980 e fim dos anos 1990), os processos locais de participação social encontram em ambos os contextos geográficos, pelo menos, dois limites críticos. Em primeiro lugar, a participação de atores diversificados é estimulada, mas nem sempre é vivida de forma eqüitativa. O termo "parceria" é corriqueiro nos discursos políticos dos atores governamentais e não-governamentais, mas sua prática efetiva parece ter dificuldades em influenciar os processos de deliberação democrática local. Em segundo lugar, os atores não-governamentais (e somente alguns deles) são consultados e solicitados durante o processo de tomada de decisões, participando, assim e no melhor dos casos, somente antes e depois da negociação. A participação praticada dessa forma pode aumentar a qualidade da transparência dos dispositivos institucionais; contudo, ela não garante, de modo necessário e automático, a legitimidade do processo institucional participativo na construção do interesse coletivo.

Daí a necessidade de, sobretudo no âmbito de pesquisas contextualizadas e de realidades específicas, se colocar em diálogo práticas que tentaram ou vêm tentando demonstrar a efetividade do princípio participativo na renovação política da democracia local. Com esse intuito, questionamos uma série de práticas de participação social no âmbito local, na América Latina e na Europa, sob duas óticas de análise: quem participa e que desigualdades subsistem na participação; e como se dá o processo de construção do interesse coletivo no âmbito dos dispositivos de participação social.

O olhar sobre duas realidades sociais e políticas tão distintas (Europa ocidental e América Latina) é proposital, e permite um enriquecimento analítico mútuo: em ambas as regiões, por razões diferentes, vive-se uma crise da democracia representativa, tanto em termos de confiança dos cidadãos nas instituições políticas quanto à capacidade das administrações públicas tornarem-se pertinentes e efetivas de acordo com as necessidades dos cidadãos. Além disso, sabe-se que, na América Latina, a democracia e a administração pública sempre foram pensadas em referência a processos históricos e cristalizações institucionais da Europa (e dos Estados Unidos). Como lembram Lavalle, Houtzager e Castello (2006), no caso das práticas de participação social, 
talvez pela primeira vez na história, a democracia e seu horizonte de reformas possíveis passaram a ser pensados, no hemisfério Norte, a partir de experiências vivenciadas no hemisfério Sul. ${ }^{1} \mathrm{O}$ interesse em contemplar experiências latino-americanas e européias de participação social justifica-se também à luz desse caráter de inovação do hemisfério Sul.

Este artigo está estruturado em três partes: a primeira apresenta o modelo teórico utilizado na análise das experiências; em segundo lugar, busca-se saber em que medida as práticas de participação social representam inovações nos modos de formular, implementar e monitorar políticas públicas locais; e, por fim, procura-se pensar o que revelam tais experiências acerca dos riscos e dos limites da participação social na formulação de políticas públicas locais, salientando inclusive o papel das agências da cooperação internacional na construção de mitos associados à participação.

\section{A construção do modelo de análise: as duas óticas principais}

Os primeiros modelos de reforma do Estado, desenvolvidos no bojo da crise da governabilidade do Estado-providência a partir dos anos 1970, restringiramse ao próprio aparelho de Estado. Estiveram fundamentados na gestão pública mínima, nas políticas de downsizing, na reforma do setor público sob a égide de uma good governance e em parâmetros de uma democracia minimalista que dão ênfase quase exclusiva às racionalidades estratégicas (Kooiman, 1993). Tiveram mais fundamento econômico que político, sua cartilha foi ditada mais por fatores externos relacionados com os programas de ajuste estrutural e menos por fatores internos próprios de cada uma das democracias nacionais. É a crise econômica que anima a reforma do Estado e de sua administração pública. No caso dos países europeus, os condicionantes externos foram reforçados pela Comissão de Bruxelas (com as receitas de ajuste fiscal e os critérios de estabilidade

\footnotetext{
${ }^{1} \mathrm{O}$ caso do Brasil é particularmente importante, não apenas por ser palco de um dos experimentos participativos mais citados na literatura (o orçamento participativo de Porto Alegre), mas por ter integrado o princípio participativo em sua Constituição. No entanto, outros países do sul também promoveram práticas, códigos e leis de participação social: por exemplo, as Filipinas com o Código do Governo Local; a Bolívia com a Lei de Participação Popular; a Cidade do México com a Lei de Participação Cidadã; ou ainda o estado de Kerala, na Índia com a "People's planning campaign". Para mais detalhes sobre os processos de reforma participativa na América Latina, ver Grindle, 1999; Gallicchio e Camejo, 2005.
} 
de Maastrich); na América Latina, foram os programas de ajuste estrutural do Fundo Monetário Internacional que marcaram (e marcam ainda) a reforma das políticas públicas. No Brasil, este processo tem vigência desde fins dos anos 1980 e início dos anos 1990, coincidindo com a redemocratização política.

No âmbito desses primeiros modelos de reforma do Estado, banalizouse a afirmação de que a participação social seria um ingrediente fundamental na prestação mais eficiente de bens públicos, inclusive e sobretudo no âmbito local. A ênfase à necessidade de considerar-se a participação dos cidadãos nos processos de formulação e gestão das políticas públicas locais tornou-se uma resposta possível à crise do bem-estar e à necessidade de rever as relações entre o governo e a sociedade na definição de estratégias de desenvolvimento local. Buscar soluções no âmbito local da gestão pública tornou-se a panacéia das crises do desenvolvimento nacional, para a qual não haveria limites ou constrangimentos no contexto da globalização contemporânea (Oliveira, 2002).

No entanto, há outros modelos de reforma da administração pública não exclusivamente ou majoritariamente orientados por fatores externos. Tais modelos não pensam de modo desconexo as diferentes escalas de governo, do local ao nacional; seus defensores concebem os objetivos da participação social de forma radicalmente distinta: ela passa a ser considerada um dos elementos do projeto de ressignificação do conceito de público. Nesse segundo conjunto de reformas da gestão pública, o aspecto político deve primar sobre o econômico; o longo prazo sobrepor-se ao curto prazo; e a racionalidade substantiva guiar as estratégias a serem definidas. A participação social implica colocar a decisão em debate (Avritzer, 2003; Dagnino, 2002). Trata-se de uma reforma democrática do Estado e de sua administração pública, que estaria embasada na necessidade de estimular a participação dos diferentes atores (governamentais e não-governamentais), dando igual ênfase à participação dos cidadãos na definição das condições de sua organização e associação. Como salienta Dagnino (2002), a legitimidade da representação política dos interesses da sociedade civil não pode ser compreendida como um cheque em branco, autorizando os governos a atuarem sem constrangimentos e cuja cobrança seria efetivada apenas na eleição seguinte. Esse modelo de democracia, denominada representativa, seria para a autora insuficiente diante da dinamicidade das necessidades da população e das experiências acumuladas que constatam as dificuldades de superar conseqüências de governos com pouco controle da sociedade. É claro que, retomando Souza (2001), cabe neste caso a pergunta central: como promover a democratização das políticas públicas via participação da sociedade em espaços de escassa infra-estrutura cívica e cidadã? 
Esse segundo conjunto de programas de reforma da gestão pública local está em curso, tanto na Europa quanto na América Latina. Não há cartilhas únicas para esse tipo de reforma, nem modelos que sejam universalmente aceitos em um ou outro continente. No entanto, há pressupostos que embasam tais programas, como a existência de cidadãos e sujeitos coletivos capazes de utilizar as regras e recursos existentes de modo reflexivo (ação reflexiva); a existência de processos políticos que contemplem oportunidades de desenvolvimento das capacidades argumentativas dos cidadãos na definição da vontade coletiva e na elaboração institucional de espaços abertos à participação; os cidadãos são considerados enquanto sujeitos capazes de produzir a normatividade em que vivem; o Estado passa a ser a instância de organização e de legitimação dos processos políticos (Cunill Grau, 2004; Blondiaux e Sintomer, 2002).

Trata-se, em última análise, de um padrão de reforma da gestão pública que se inspira nos pressupostos da democracia deliberativa (Elster, 1998; Fishkin, 1991; Habermas, 1990). Reconhece, por exemplo, que o Estado perde o monopólio de produção e proteção do bem público, porquanto surge com força a idéia do público não-estatal deslocando interesses e papéis para a sociedade civil. Existe uma maior complexidade do sistema de decisão sobre o fazer política: a decisão não é mais exclusivamente governamental; o governo é central, mas é menor que os chamados sistemas de governança. Existe distribuição de poder no processo de decisão entre diversos atores; há um intenso processo de negociação e definição das regras para a tomada de decisões; criase a necessidade de descentralizar as decisões e os recursos; a participação social é central, mas a capacidade de participação dos atores é diferenciada.

No âmbito desse segundo conjunto de reformas da administração pública, como considerar a participação social em processos de tomada de decisão para a formulação de políticas públicas locais? Na deliberação democrática, o mundo das instituições políticas se abre aos atores da sociedade civil com o objetivo ideal de compartilhar a responsabilidade da decisão política e de construir consensos sobre os conteúdos da política pública local. ${ }^{2}$ Para que o governar localmente adquira relevância política nesse segundo conjunto de reformas do Estado e da administração pública, é essencial conceber políticas

\footnotetext{
${ }^{2}$ Salientamos que a participação pode igualmente ser considerada: na sua dimensão pedagógica (por exemplo, segundo os princípios de uma educação para a emancipação política e por uma cidadania ativa); como controle social da gestão das políticas públicas (sem necessariamente participar da sua implementação); na sua dimensão simbólica (e aqui, participar contribui, por exemplo, para construir uma identidade coletiva de um movimento social); e como conquista política que, nesse caso, significa conquistar direitos, uma vez que as políticas sociais distribuem não somente bens, mas igualmente poder (Teixeira, 2002).
} 
efetivas de descentralização de meios e recursos, que é fundamental na construção da institucionalidade participativa, visto que não haveria nada mais desgastante para a participação do cidadão e das organizações da sociedade civil do que uma série de discussões sem a posterior implementação das decisões (Paddison, 1999). Isso porque a participação social tem, nesse caso, o sentido de apelo e convocação dos cidadãos e das organizações da sociedade civil para compartilhar a decisão em matéria de políticas públicas locais. ${ }^{3}$

Portanto, do ponto de vista analítico, o apelo ao cidadão e às organizações da sociedade civil para que participem da formulação de políticas públicas locais pode ser visto em três níveis. Em primeiro lugar, a participação pode significar controlar a qualidade dos serviços prestados. Isso significa que a participação cidadã na prestação de serviços sociais pode aumentar a qualidade dos resultados obtidos ao contrapor-se às formas monopólicas de produção de serviços sociais (Cunill Grau, 2004). Ela pode ajudar a incrementar a efetividade dos serviços sociais, tornando os gastos mais eficientes. Em segundo lugar, a participação pode significar a expressão de prioridades acerca de bens públicos futuros. No entanto, é bem verdade que, tanto no primeiro quanto no segundo casos, a participação não remete automaticamente a momentos de deliberação. Em terceiro lugar, participar pode ser sinônimo de politizar as relações sociais no processo de constituição de espaços públicos para a formulação de políticas públicas locais.

No entanto, de que tipo de participação se trata? Participação em quê? Para quê? Como? Além disso, quem participa? Quem são os cidadãos e as organizações autorizados a participar? E em que espaços de decisão ou canais de participação podem participar? De fato, são inúmeros os questionamentos necessários para se fazer uma análise empírica das políticas públicas locais à luz do princípio participativo. ${ }^{4}$ Neste artigo, nossa análise está fundada em duas ordens de questionamentos:

\footnotetext{
${ }^{3}$ Se sobrepõem vários discursos que utilizam a participação, incluindo a demagogia populista e o assistencialismo filantrópico. Daí a necessidade analítica de pensar concomitantemente discursos e práticas políticas efetivas, experimentadas e reconhecidas. Uma análise dessa natureza não deve ser confundida com os bancos de dados de best practices dos organismos internacionais, visto que não recebem uma etiqueta de qualidade, mas são simplesmente descritas analiticamente (Burnell, 1997; Escobar, 1994; Guijt e Shah, 1998).

${ }^{4}$ Desenvolvemos um roteiro analítico de questões que podem guiar futuros trabalhos de sistematização crítica de experiências e práticas de participação no âmbito local. Não pretendemos, com o roteiro desenvolvido, esgotar as interrogações possíveis, mas simplesmente propor uma primeira aproximação metodológica sempre passível de debate e contextualização, mas que pode orientar futuras pesquisas no vasto campo da participação local. O roteiro está disponível em: $<$ www.adm.ufba.br/capitalsocial >, que apresenta resultados de um projeto desenvolvido com o apoio da Fapesb, Fundação de Apoio à Pesquisa do Estado da Bahia.
} 
จ a primeira questão que norteou nossa análise das 10 experiências foi a seguinte: quem participa? Uma vez que sabemos que a participação social pode, ao mesmo tempo, levar à constituição de interesses corporativos nos processos de decisão e dar vazão às vozes específicas de sujeitos subalternos na economia e na política, parece-nos essencial interrogar as diferentes experiências sobre o perfil da participação. Trata-se de indivíduos, cidadãos, atores sociais, atores institucionais, atores econômicos, atores da sociedade civil? Participam enquanto indivíduos ou grupo (ou representando um grupo)? Há uma profissionalização da participação? Há diversidade na participação? Além disso, que desigualdades subsistem na participação?

v em segundo lugar, como se dá o processo de construção do interesse coletivo no âmbito das políticas públicas locais analisadas? Trata-se de um processo consultivo ou deliberativo? Quais são as relações entre o interesse particular, o corporativo e o geral?

A resposta a tais questões é mais fácil na teoria e muito difícil na análise da prática da gestão local que se diz participativa, já que diz respeito à democratização dos processos políticos. Sabemos que a participação social cidadã é aquela que configura formas de intervenção individual e coletiva, que supõem redes de interação variadas e complexas determinadas (proveniente da "qualidade" da cidadania) por relações entre pessoas, grupos e instituições com o Estado. A participação social deriva de uma concepção de cidadania ativa. A cidadania define os que pertencem (inclusão) e os que não se integram à comunidade política (exclusão); logo, a participação se desenvolve em esferas sempre marcadas também por relações de conflito e pode comportar manipulação. ${ }^{5}$ Os atores políticos, ao decidirem pela participação, podem ter objetivos muito diversos, tais como a autopromoção, a realização da cidadania,

\footnotetext{
${ }^{5}$ Retomando a teoria marshalliana da cidadania, a participação parte de uma perspectiva fundada nos direitos e nos deveres dos cidadãos na sua relação com as políticas sociais e da noção de cidadania arraigada no compromisso social. Ou seja, o pressuposto é de que, por meio da participação, é possível construir a cidadania e fortalecer os direitos sociais. No entanto, o conceito de cidadania (que serve para determinar quem são os membros da polis ou da comunidade política ou para indicar quem é o demos) é um conceito historicamente controvertido. Ou seja, não são somente as noções de cidadania e participação que (exclusivamente) dão sentido à democracia. Dizer que a democracia é a forma de governo onde os cidadãos participam é uma meia-verdade, já que temos de esclarecer quem são os cidadãos, de que participação se trata e quais são as suas modalidades. Uma das dimensões da cidadania diz respeito à liberdade positiva, entendida como a faculdade dos indivíduos participarem na adoção das decisões a que se verão submetidos na vida pública. Mas, para ser democrática, a participação deve ser livre (isenta de condicionamentos e dada a partir de opções ou alternativas reais e não fictícias) e deve canalizar-se mediante procedimentos preestabelecidos e conhecidos daqueles que participam.
} 
a implementação de regras democráticas, o controle do poder burocrático, a negociação ou inclusive a mudança progressiva de cultura política.

\section{Experiências de participação cidadã na América Latina e na Europa ocidental: renovação das políticas públicas locais?}

As múltiplas razões do crescente interesse pela introdução da participação dos cidadãos na gestão pública local, tanto na América Latina quanto na Europa ocidental, dizem respeito à crise de credibilidade da democracia representativa marcada pela apatia política dos eleitores, considerável descaso popular por assuntos públicos, significativas taxas de abstenção eleitoral (nos casos em que o voto não é obrigatório), e níveis elevados de corrupção na administração pública. Há uma demanda claramente formulada por atores da sociedade civil em prol da renovação das relações governo-sociedade e de uma redefinição da representação política, uma vez que a representação tradicional se encontra cada vez mais distante da vontade dos representados.

São inúmeras as experiências de participação social na América Latina e na Europa ocidental: orçamentos participativos, conselhos de políticas públicas, fóruns e redes de desenvolvimento local, círculos de estudos, conferências de construção de consenso, pesquisas deliberativas, júris de cidadãos, entre outras (Font, 2001; Ziccardi, 2004). Algumas delas remetem-nos ao processo de construção da cidadania e à promoção do protagonismo autônomo da sociedade civil, ao passo que outras são iniciativas do poder público no âmbito de políticas de descentralização e modernização do Estado (na esfera subnacional). No entanto, não há como pensar as experiências de participação social sem relacionálas com as histórias políticas nacionais, a tradição cívica local, a cultura política e as estruturas de desigualdade socioeconômica de cada contexto. Ou seja, não há modelos únicos e universais, porquanto os projetos políticos e culturais são muito distintos de acordo com os contextos que são muito variados.

No Brasil, por exemplo, a participação é um elemento central nos processos de reforma democrática do Estado desde a Constituição de 1988. Esta estimula a participação popular na tomada de decisões sobre políticas públicas, como no caso do princípio de cooperação com associações e movimentos sociais no planejamento municipal (art. 29) ou de participação direta da população na gestão administrativa da saúde, previdência, assistência social, educação e criança e adolescente (arts. 194, 198, 204, 206 e 227). Isso não significa, evidentemente, que os padrões de cultura política local e regional (com as marcantes distinções entre o Sul e o Nordeste brasileiros, por exemplo) não sejam fatores determinantes na condução de políticas públicas participativas: 
a tabela abaixo apresenta sinteticamente a distribuição de experiências de orçamento participativo municipal no Brasil e a importância quantitativa das práticas desenvolvidas nas regiões Sul e Sudeste do país, regiões estas que apresentam indicadores sociais, padrões de comportamento político e capital social diferenciado em comparação ao restante do país. Como assinalam Fuks e Perissinotto (2006), ao analisar experiências de conselhos gestores de políticas públicas na cidade de Curitiba, é fundamental levar em conta, além das interações observáveis no processo decisório e os recursos possuídos pelos atores políticos, o contexto (interno e externo) como elemento que afeta a conduta política dos atores dentro dos conselhos. Esse contexto é determinado por uma série de aspectos, tais como a existência de arenas alternativas, o desenho institucional dos conselhos, a interferência do governo na eleição dos representantes não-governamentais, a existência de valores e ethos específicos de cada policy domain, bem como a natureza da relação entre governo e sociedade civil (diretamente influenciada pelo grau de associativismo e a orientação ideológica do Poder Executivo). Isso significa, evidentemente, que os limites socioeconômicos, simbólicos e políticos funcionam como obstáculos relevantes à participação, podendo inclusive aprofundar a desigualdade política no âmbito dos próprios dispositivos participativos (Fuks e Perissinotto, 2006).

\section{Distribuição do orçamento participativo por região} (1997-2000)

\begin{tabular}{|lcc|}
\hline Região & Número de municípios & $\%$ \\
\hline Sudeste & 47 & 45,6 \\
Sul & 39 & 37,8 \\
Nordeste & 14 & 13,6 \\
Norte & 3 & 3 \\
Total & 103 & 100 \\
\hline
\end{tabular}

Fonte: Torres Ribeiro e Grazia, 2003.

Levando em consideração o aspecto relativo à multiplicidade dos contextos e seus fatores, e buscando contribuir com as reflexões deste artigo, nosso olhar dirigiu-se para cinco experiências latino-americanas de gestão participativa e outras cinco européias. ${ }^{6}$ São experiências iniciadas pelo po-

\footnotetext{
${ }^{6}$ As 10 experiências, selecionadas com base na história acumulada de lições (acertos e erros) e no reconhecimento por instâncias governamentais e centros de pesquisa, foram apresentadas e discutidas em um colóquio internacional, sob a coordenação científica do autor deste artigo, na cidade de Poitiers (França), em junho de 2005. Foi um evento organizado pelo Instituto de Estudos Políticos de Paris, no âmbito do Ano do Brasil na França. Algumas informações estão disponíveis
} 
der público (em matéria de planejamento urbano-territorial e de orçamentos participativos) ou pela sociedade civil (mobilização e organizações de base comunitária). O quadro 1 apresenta-as resumidamente.

$$
\text { Quadro } 1
$$

\section{Experiências de participação social (América Latina e Europa)}

\begin{tabular}{|c|c|c|c|c|}
\hline & $\begin{array}{l}\text { Identificação } \\
\text { da experiência }\end{array}$ & País & Município & $\begin{array}{l}\text { Origem da } \\
\text { iniciativa e data }\end{array}$ \\
\hline \multirow[t]{5}{*}{$\begin{array}{l}\text { América } \\
\text { Latina }\end{array}$} & Planejamento estratégico & Argentina & Córdoba & $\begin{array}{l}\text { Poder público (1990, com } \\
\text { interrupções) }\end{array}$ \\
\hline & Planejamento urbano & Brasil & Belo Horizonte & Poder público (desde 1993) \\
\hline & Orçamento participativo* & Brasil & Porto Alegre & Poder público (desde 1989) \\
\hline & Planejamento local & Costa Rica & Asserí & $\begin{array}{l}\text { Poder público e cooperação } \\
\text { internacional (desde 2002) }\end{array}$ \\
\hline & $\begin{array}{l}\text { Comitê de defesa dos } \\
\text { direitos dos moradores } \\
\text { de bairros (Copadeba) }\end{array}$ & $\begin{array}{l}\text { República } \\
\text { Dominicana }\end{array}$ & Santo Domingo & $\begin{array}{l}\text { Sociedade civil (desde } \\
\text { 1978) }\end{array}$ \\
\hline \multirow{5}{*}{$\begin{array}{l}\text { Europa } \\
\text { ocidental }\end{array}$} & Orçamento participativo & Alemanha & Hilden & Poder público (desde 2001) \\
\hline & Orçamento participativo & Espanha & Córdoba & Poder público (desde 2001) \\
\hline & $\begin{array}{l}\text { Orçamento participativo } \\
\text { nas escolas }\end{array}$ & França & Poitiers** & Poder público (desde 2004) \\
\hline & $\begin{array}{l}\text { Construção participativa } \\
\text { da regulação do verde } \\
\text { público urbano }\end{array}$ & Itália & Veneza & $\begin{array}{l}\text { Universidade (entre } 2001 \text { e } \\
\text { 2003)*** }\end{array}$ \\
\hline & Planejamento urbano & Itália & Roma & Poder público (desde 1994) \\
\hline
\end{tabular}

* No que tange às experiências de Porto Alegre e Córdoba (Argentina), nossa análise também partiu dos estudos prévios de Echevarría (2005), Fedozzi (2000), Marquetti (2003) e Navarro (2003).

** No caso de Poitiers, a iniciativa de orçamento participativo nas escolas de ensino médio ("lycées") engloba, além do município, toda a região do Poitou-Charentes.

*** Há inúmeras outras experiências mediadas pelo Centro Ombrello, do Instituto Universitário de Arquitetura de Veneza (luav). A data indica somente o período de negociação e deliberação sobre a regulação do verde público urbano, não o de fundação da organização.

em: <www.iberoamerica.sciences-po.fr > Nossos sinceros agradecimentos, pelos dados que nos foram transmitidos e pelas entrevistas a Isabel Rauber, Carsten Herzeberg, David Recondo, Maria Fernandes Caldas, Sophie Bouchet-Petersen, Yves Sintomer, Luciano Brunet, Giobanni Allegretti, Germán Solinís, Corina Echavarría, Valeria Giannella, Jean-Paul Vargas, Ernesto Ganuza, Leonardo Avritzer, Loïc Blondiaux e Olivier Dabène. Metodologicamente, foram realizadas entrevistas semi-estruturadas com alguns dos gestores diretamente envolvidos na implementação das experiências, entrevistas com pesquisadores nacionais e locais, além da análise de material informativo e relatórios de avaliação produzidos no âmbito de cada experiência. 
Ainda que não seja nosso objetivo apresentar cada uma das 10 experiências com a riqueza de seus detalhes históricos, seus procedimentos metodológicos e processos políticos, pois ultrapassaríamos o escopo deste artigo, parece-nos fundamental buscar elementos analíticos que as aproximam e as distanciam. Ou seja, é essencial compreender algumas de suas particularidades, sobretudo no que diz respeito às três óticas anunciadas anteriormente no artigo.

\section{Qual seria o perfil do participante e que desigualdades subsistem na participação social?}

Como lembra Cunill Grau (2004), as desigualdades na representação política e social dentro dos processos de formação da vontade política influenciam a composição da agenda social e, portanto, dificilmente o reconhecimento pelo Estado dos direitos sociais pode prescindir da democratização dos processos e instâncias de definição de políticas públicas e alocação de recursos. No entanto, como afirma Ziccardi (2004), uma característica central dos processos participativos é a intensidade desigualmente distribuída; outra seria a falta de representatividade social do universo de pessoas e organizações que participam. Como em muitas outras experiências de participação social, nos 10 casos aqui descritos, há poucos dados qualitativos detalhados sobre o perfil dos participantes, além do que sintetiza o quadro 2 .

\section{Quadro 2}

\section{Breve descrição sobre o perfil da participação}

\begin{tabular}{|ll|}
\hline Experiências & Quem é chamado a participar? Quem participa? \\
\hline $\begin{array}{l}\text { Córdoba } \\
\text { (Argentina) }\end{array}$ & $\begin{array}{l}\text { Cidadãos, associações profissionais e técnicas, sindicatos, federações industriais, } \\
\text { grupos religiosos, universitários, representantes de programas das Nações Unidas } \\
\text { (observadores do processo). }\end{array}$ \\
Belo Horizonte & $\begin{array}{l}\text { Cidadãos, representantes do setor privado e associações locais, delegados das } \\
\text { conferências municipais de políticas urbanas, membros do Conselho Municipal } \\
\text { de Política Urbana (Compur), constituído de } 16 \text { membros, sendo oito do Poder }\end{array}$ \\
& $\begin{array}{l}\text { Executivo, um do Poder Legislativo e seis representantes da sociedade civil (setores } \\
\text { técnico, empresarial e popular). }\end{array}$ \\
& $\begin{array}{l}\text { Cidadãos, delegados e conselheiros do OP, além de representantes da União das } \\
\text { Porto Alegreciaçóes de Moradores de Porto Alegre (Uampa) e do Sindicato dos Servidores } \\
\text { do Município (Simpa). }\end{array}$ \\
\hline
\end{tabular}




\begin{tabular}{|c|c|}
\hline Experiências & Quem é chamado a participar? Quem participa? \\
\hline Asserí & $\begin{array}{l}\text { Associações de moradores, grupos religiosos, associações desportivas e setores } \\
\text { empresariais locais. }\end{array}$ \\
\hline $\begin{array}{l}\text { Santo } \\
\text { Domingo }\end{array}$ & $\begin{array}{l}\text { Indivíduos, movimentos sociais, associações de moradores, clubes de bairro, } \\
\text { representantes de partidos políticos, ONGs locais e universitários (mediadores } \\
\text { locais e externos ao município). }\end{array}$ \\
\hline Hilden & Cidadãos nacionais e estrangeiros, gestores governamentais. \\
\hline $\begin{array}{l}\text { Córdoba } \\
\text { (Espanha) }\end{array}$ & $\begin{array}{l}\text { Cidadãos individuais, cidadãos organizados em associações e gestores } \\
\text { governamentais. }\end{array}$ \\
\hline Poitiers & $\begin{array}{l}\text { Diretores de escolas, estudantes, funcionários administrativos, pais e mães, } \\
\text { gestores governamentais e consultores (mediadores externos ao município). }\end{array}$ \\
\hline Veneza & $\begin{array}{l}\text { Cidadãos, grupos de moradores, técnicos em planejamento da prefeitura, } \\
\text { representantes do poder público local, além dos mediadores locais do Instituto } \\
\text { Universitário de Arquitetura de Veneza e da ONG Ombrello. }\end{array}$ \\
\hline Roma & $\begin{array}{l}\text { Cidadãos italianos e estrangeiros, com maior ênfase para cidadãos jovens, } \\
\text { além de técnicos de planejamento urbano, associações locais, universitários e } \\
\text { consultores (mediadores locais e externos ao município). }\end{array}$ \\
\hline
\end{tabular}

No caso de Hilden, contabiliza-se que aproximadamente $22 \%$ do total dos participantes têm entre 51 e 60 anos; 56,9\% têm mais de 61 anos; os estrangeiros são $2,6 \%$; os desempregados não participam. ${ }^{7}$ No caso de Porto Alegre, dados divulgados pela Organização Guayi ressaltam que participaram cerca de 33.625 pessoas (em 2002) e 27.608 pessoas (em 2003), consideradas as duas rodadas do OP. Ainda acerca do OP em Porto Alegre, Fedozzi (2000) aponta que o típico participante, no ano de 1995, era o público constituído de forma paritária entre homens e mulheres, com até 41 anos de idade, cor branca, renda familiar de até cinco salários mínimos e escolaridade de até o primeiro grau completo; em 1997, esse perfil já se modificara e seria o seguinte: mulher, casada, com mais de 34 anos de idade, com renda familiar de até quatro salários mínimos, escolaridade até o primeiro grau e atuante em associação de moradores. Em Poitiers, o OP das escolas de ensino médio concerne 52 estabelecimentos, com um total de 32.903 estudantes; durante o primeiro ano de experiência, em 2005, participaram 4.020 indivíduos (entre diretores, estudantes, funcionários, pais e mães).

Ressalta-se que a totalidade das experiências enseja a participação de cidadãos a título individual. Os indivíduos podem integrar os mecanismos de

${ }^{7}$ Dados apresentados por Carsten Herzeberg em Poitiers, em junho de 2005 (vide nota 6). 
participação sem que estejam, necessariamente, organizados em grupos ou representando associações. No entanto, são muitas as desigualdades reveladas na prática das experiências analisadas, por exemplo, no que concerne à participação de homens e mulheres: em Santo Domingo, as mulheres são bastante dinâmicas no processo de negociação nos bairros, mas têm pouca inserção nos órgãos de decisão e de representação do Copadeba, assim como no diálogo com o poder local (Rauber et al., 2000). Em Asserí, os homens são a grande maioria. Em Hilden, cerca de 65\% dos participantes são homens. Em Poitiers, a mais recente das experiências analisadas, as hierarquias entre os diretores das escolas e os demais atores do processo (sobretudo os estudantes e os funcionários) tendem a inibir uma participação de contestação. Ademais, alguns gestores das 10 experiências que foram entrevistados pelo autor relembram que existem desigualdades quanto à qualidade da participação das associações: algumas estruturas associativas são menos sólidas e coordenadas, não podendo assegurar, ao longo do processo, todos os custos relativos à participação social (por exemplo, no que diz respeito ao monitoramento do processo e à sua conseqüente sistematização).

Um aspecto importante a ser salientado é que, em todas as experiências, os números da participação são bastante modestos se pensados em relação à população local. Aqui se desfaz um dos imaginários que se criam em torno dos processos participativos locais: como ressalta Navarro (2003), ao analisar o OP de Porto Alegre, é importante afirmar que os municípios não vivem em permanente estado de euforia associativa e participativa. A assimetria de conhecimentos e informações, mas também de implicação política, faz com que poucos cidadãos se mobilizem e participem efetivamente das experiências de gestão pública participativa. É evidente, porém, que não se pode julgar o potencial de renovação democrática dessas experiências exclusivamente pela quantidade de participantes efetivamente mobilizados: não se trata somente de estimular as pessoas a participarem mais do processo de formulação de políticas públicas locais, mas de assegurar a qualidade dessa participação sobretudo em sua perspectiva pedagógica e deliberativa, como lembra Joan Subirats (2001).

\section{A gestão participativa é um processo de natureza consultiva ou deliberativa?}

Quanto à deliberação e ao processo de construção da vontade coletiva, os contextos são muito diversos. Em Asserí, a capacidade de controle pelos cidadãos 
sobre a implementação das decisões é bastante reduzida, visto que inexistem espaços de monitoramento das políticas locais e a descentralização é, ainda, um processo incipiente. Além disso, a cultura política local é profundamente marcada pelo clientelismo.

No caso de Córdoba (Argentina), o planejamento estratégico não é espaço deliberativo. Quanto à circulação de informação, por exemplo, os participantes não manifestam clareza acerca das diferentes etapas do planejamento estratégico participativo, ou sequer de sua posição no processo, de seus direitos e seus deveres. Trata-se fundamentalmente de uma modernização da gestão pública local promovida de cima para baixo: o Executivo local desconcentra o processo de tomada de decisões a fim de interpretar as necessidades sociais. Para tanto, a participação está associada a processos de consulta de entidades acadêmicas e profissionais; os cidadãos, em seus bairros, participam da organização, execução e financiamento de obras públicas. Como lembra Echevarría (2005), segundo os próprios gestores de Córdoba, o município é considerado um espaço para o debate e a negociação entre distintos atores e idéias. Inserida no paradigma da "boa governança", a experiência busca, sobretudo, desverticalizar a gestão local (Echevarría, 2005).

Em Hilden, o orçamento participativo também é expressão do projeto de modernização da gestão pública municipal na implementação de suas novas políticas de bem-estar: ele visa melhorar a transparência das finanças públicas municipais e facilitar o acesso dos cidadãos à administração pública local. O processo do OP em Hilden (que evita, ao máximo, o risco da politização) é de consulta e não de deliberação; as regras são claras, mas dão pouca margem à autonomia da sociedade civil. A metodologia adotada, por meio da qual os participantes são sorteados, promove baixo nível de diálogo horizontal.

Os casos de Porto Alegre e Córdoba (Espanha) aproximam-se bastante, salvo pela mais ampla experiência do primeiro em relação ao segundo. Em Córdoba (Espanha), o orçamento participativo foi lançado em 2003, não tendo, ainda, repercussões no que tange aos critérios de justiça social e distribuição de recursos, como em Porto Alegre (Marquetti, 2003). Em ambos, o processo deliberativo é marcado pela votação direta dos cidadãos, pela existência de códigos internos revisados regularmente e pela organização cíclica de assembléias territoriais e temáticas. Ambos foram lançados por governos locais de esquerda (PT, em Porto Alegre e Psoe, seguido pela Izquierda Unida, em Córdoba) e contam com conselhos de monitoramento do processo.

No caso do OP das escolas de ensino médio em Poitiers, está em deliberação um montante de $€ 10$ milhões do orçamento de investimentos da região do Poitou-Charentes para projetos de infra-estrutura e melhorias do meio am- 
biente escolar (ou seja, 10\% do total do orçamento). A deliberação também é cíclica, incluindo duas reuniões (a primeira para expor e discutir os projetos existentes e a segunda para votar as prioridades). Durante a segunda reunião, cada participante dispõe de 10 boletins a fim de votar nos projetos de acordo com seu livre-arbítrio. Os gestores da autoridade local analisam e explicam a factibilidade técnica e financeira dos projetos. As instâncias representativas das escolas (Conselho de Administração e Conseil de la Vie Lycéenne) são informadas e pronunciam-se sobre as escolhas, mas não têm a possibilidade de revogar as prioridades preestabelecidas. Ao final, é organizada uma assembléia regional para apresentar e votar os projetos escolhidos nas reuniões de cada escola. Em 2004, dos 40 projetos escolhidos e priorizados nas escolas, três foram classificados como prioritários. Ao final, cada escola recebe um relatório sobre as conclusões do processo participativo.

Em Belo Horizonte, o processo deliberativo de planejamento urbano também é cíclico, englobando reuniões de informação, conferências temáticas e regionais, oficina de capacitação dos delegados e a conferência municipal de política urbana. A incorporação da dimensão do diálogo e da deliberação no seio do planejamento urbano de Belo Horizonte ajuda a romper com dois traços distintivos tradicionais da gestão pública local: a segmentação e a verticalidade. Belo Horizonte também conta com dois orçamentos participativos, mas eles não integraram a nossa análise.

O caso de Roma é bastante particular, já que há um uso de múltiplos dispositivos participativos (laboratórios territoriais permanentes, contratos de bairros e orçamento participativo). Tais dispositivos não se desenvolvem sem causar problemas na relação entre o Poder Executivo local e os conselhos municipais (câmaras de vereadores), sobretudo no que diz respeito à concepção dos orçamentos e dos planos diretores urbanos. O caráter deliberativo dos dispositivos causa problemas com o Legislativo local, sobretudo porque existe, além da vontade política do Executivo local, autonomia financeira para a implementação das decisões. A descentralização e a criação dos 20 distritos municipais, que são espaços de mediação e de regulação de conflitos políticos (por exemplo, entre as iniciativas institucionalizadas e as autônomas da sociedade civil), conduzem a uma politização dos processos participativos.

Aspecto interessante do caso romano, o prefeito Walter Veltroni (em 2005) contava com índices de aprovação acima dos $80 \%$. A influência da experiência faz com que se desenvolva a consciência de que os cidadãos devem participar da formulação de políticas públicas locais e não apenas de projetos pontuais. Em 2002, um grupo de universitários escreveu a Carta do Novo Município, assinada por 300 prefeitos italianos e apresentada no Fórum Social 
Mundial de Porto Alegre; como decorrência, construiu-se uma rede de municípios, províncias, universidades, associações e indivíduos interessados em experimentar instrumentos participativos a partir de novos conteúdos (economia solidária, sustentabilidade ambiental, luta contra a privatização de bens comuns etc.) e em intercambiar aprendizados e ferramentas de gestão. No entanto, essa influência da experiência romana na Itália se dá mais no plano das plataformas políticas dos partidos e dos executivos. A participação social é vista como uma possibilidade de abertura de caixas fechadas e como espaço no qual se desenvolvem novos programas políticos (Allegretti, 2003).

Em Santo Domingo, são realizadas assembléias por comitê de quadra, por bairro, por zonas e, finalmente, organiza-se a assembléia geral do Copadeba. Todas as propostas são redigidas e difundidas, mesmo que não tenham recebido um único voto no âmbito do bairro. A formação política dos cidadãos integra a experiência de participação cidadã: desde a confecção do diagnóstico, passando pela elaboração de propostas, até a definição dos termos da negociação com as autoridades locais, a deliberação é um processo que se torna pedagógico-político, sobretudo a partir da ação das comunidades eclesiais de base e das experiências de educação popular. A participação é estimulada por critérios temáticos e territoriais; ela é, segundo Rauber (1994), sinônimo de presença no cotidiano, compromisso com o processo decisório, a tomada de decisões, mas é igualmente uma reflexão e uma ação com ritmos muito lentos.

Em Veneza, experiência que se insere em perspectiva bastante próxima do que foi relatado para o caso de Santo Domingo, existe uma mediação local na definição de sistemas de regulação públicos urbanos. O trabalho realizado pelo Centro Ombrello tem a particularidade de ser uma mediação, oferecida no âmbito da universidade (Departamento de Planejamento Urbano e Territorial), que parte da premissa de que é necessário valorizar os diferentes tipos de competência e de saberes na construção de sistemas de regulação sobre o uso de bens públicos (parques, rodovias, estradas e equipamentos urbanos). Há, nesse sentido, uma ênfase importante dada a dimensão pedagógica da participação: a pedagogia da participação é veiculada como meio a fim de superar o conflito entre atores e promover a noção de responsabilidade compartilhada.

\section{Riscos e limites da participação social na formulação de políticas públicas locais}

Há uma série de elementos presentes nas experiências analisadas que podem contribuir para a renovação das políticas públicas locais, trazendo respostas às 
contradições intensificadas pela globalização econômica no campo social, produzindo novos mecanismos de co-gestão, diversificando as alianças sociais ou tentando converter o espaço local em novo lócus de solidariedade cívica. Não se trata, contudo, de uma tarefa fácil, como bem demonstram as experiências brevemente descritas, visto que, sobretudo no caso da América Latina, em poucos países se pôde efetivamente construir um mínimo básico de bem-estar social. Além disso, na América Latina e na Europa, a visão social do Estado goza atualmente de pouco crédito, tendo assumido caráter populista ou sendo investido pelo cânone neoliberal.

Entre os riscos mais freqüentes, presentes nas experiências discutidas, salientamos o caráter dispersivo das iniciativas dos governos locais que pode debilitar o conjunto da política social. A menos que sejam construídas redes de coordenação efetiva entre os governos locais e os outros níveis de governo, a ausência de mecanismos institucionais que garantam as regras contínuas do fazer políticas públicas no âmbito local pode levar à fragmentação das experiências e à diferenciação dos direitos e serviços acessíveis em um mesmo território nacional. Na América Latina, como lembra Cabrero (2004), muitos programas de origem federal (implementados a partir do centro para as localidades) tendem a ser mais cuidadosos e fundados em critérios mais profissionais e rigorosos; eles tendem, porém, a conter fortes inércias burocráticas e alto grau de rigidez na implementação, aspectos que pouco entusiasmam os cidadãos. No caso dos programas locais, a visão de curto prazo prima sobre a de longo prazo; eles tendem a ter um desenho técnico mais improvisado, sendo implementados por funcionários locais com baixos níveis de profissionalização; além disso, sofrem de imprevisibilidades orçamentárias. Já os programas locais, sobretudo ao dar ênfase à participação social, gozam de muita legitimidade, credibilidade e confiança junto à população (Cabrero, 2004).

Um segundo limite associado à formulação de políticas públicas locais participativas diz respeito à forma como a institucionalidade participativa é vivenciada e à conseqüente falta de sustentabilidade dos programas. Ainda que tenham forte componente pedagógico e cívico, as experiências participativas podem incorrer no risco da diluição das responsabilidades por ausência de instâncias formais e institucionais. ${ }^{8}$ No caso das políticas públicas locais,

\footnotetext{
${ }^{8} \mathrm{O}$ caso do OP de Porto Alegre é analisado nesses termos por Echevarría, Corina. Espaço público e institucionalização: resistência à organização formal do "Plan estratégico de la Ciudad de Córdoba" (Argentina) e do Orçamento Participativo de Porto Alegre (Brasil). 2005. Tese (Doutorado) - Salvador: UFBA (orientadora: Susana Moura).
} 
um ambiente de relações entre governo e sociedade marcado pela espontaneidade, pelo voluntarismo coletivo e por estratégias de curto prazo impostas pelo sistema eleitoral, pode impedir a concretização dos resultados na fase de instalação de uma política social. Muitos programas sociais são interrompidos causando graves problemas para os cidadãos-beneficiários. A participação, como ação coletiva, pode esgotar-se no processo e não ser um fator de estímulo à continuidade das políticas públicas. Ela gera custos e, além disso, a nãoobtenção de benefícios observáveis e o fato de não se inscrever em acordos institucionais mais sólidos podem contribuir para a interrupção de políticas locais, sobretudo no campo social.

Paradoxalmente, a institucionalização de experiências de participação cidadã pode cair na armadilha da burocratização do processo de participação em um esquema mais corporativo. A criação de instâncias formais pode corresponder ao início da cristalização do processo social de participação. A experiência do Centro Ombrello, em Veneza, mostra o quanto é essencial tentar evitar essa armadilha e fazer com que a participação conduza a uma reinterpretação do sentido das políticas públicas locais, subvertendo as relações tradicionais entre os atores e abrindo espaços para que novos atores tenham voz. Eles são considerados, no jargão do Centro Ombrello, novos sujeitos públicos.

\section{A ambigüidade do papel das agências da cooperação internacional}

Em dois casos (Córdoba, na Argentina; e Asserí), o apoio de agências internacionais (Pnud e GTZ, respectivamente) foi essencial para o início e o desenvolvimento das experiências. Em Santo Domingo, agências governamentais e não-governamentais internacionais financiam, ainda hoje, muitas atividades do Copadeba (Misereor, Oxfam Reino Unido, Agência Sueca de Desenvolvimento Internacional, Habitat Internacional, entre outras). Em Asserí, a assistência técnica é prestada na constituição e na formação dos conselhos distritais de planejamento urbano. Em Córdoba (Argentina), houve o apoio financeiro para a implementação do processo de planejamento estratégico pelo BID e pelo Pnud. O orçamento participativo de Porto Alegre é venerado como best practice pelo Pnud e pelo Banco Mundial. Também graças à difusão assegurada pelas agências de cooperação (governamentais e não-governamentais), muitas experiências européias inspiram-se nesses êxitos da democracia local latino-americana sem necessariamente conhecer mais de perto suas contradições e lacunas. Ou seja, programas e projetos de agências bilaterais e multilaterais podem contribuir para mistificar as experiências de participação social 
que existem na América Latina e na Europa e dessa mistificação decorrem riscos importantes para gestão participativa de políticas públicas locais, que passamos a analisar a seguir.

Vários documentos nos anos 1990 colocam a participação no centro do debate sobre práticas de desenvolvimento. É o caso, por exemplo, do Human Development Report de 1993, publicado pelo Pnud, que tenta examinar como e de que forma as pessoas participam de eventos e processos que têm implicações sobre suas vidas, sob a perspectiva de três grandes olhares: os mercados solidários, a governança descentralizada e as organizações comunitárias (UNDP, 1993). A publicação, pelo Banco Mundial, em 1999, de Voices of the Poor, teve significativa repercussão no mundo da cooperação internacional e contribuiu muito para a disseminação de práticas participativas em projetos de desenvolvimento. A disseminação de tais documentos veio, evidentemente, nutrir a reflexão sobre os programas de reformas da administração pública local. Como já assinalaram inúmeros autores (Escobar, 1994; Cooke e Kothari, 2001), subsistem ainda hoje práticas relacionadas à cooperação internacional que têm grande impacto na definição de prioridades para a gestão pública local.

Em que consiste, esquemática e resumidamente, essa mistificação? Primeiramente, práticas participativas podem incorrer na armadilha do chamado "mito da comunidade" (Guijt e Shah, 1998), ou seja, uma visão ingênua e simplificada do que seria a comunidade (sempre homogênea, estática e harmônica) e das pessoas que nela convivem (sempre compartilhando valores, interesses e necessidades comuns). Nessa visão paradisíaca da comunidade, não haveria diferenças de idade, classe, gênero, casta, etnicidade ou religião; não haveria tampouco o risco da construção do consenso comunitário mascarar as diferenças ou dar legitimidade a algumas diferenças e não a outras. Algumas das desigualdades evidenciadas em termos de participação que discutimos no contexto das 10 experiências latino-americanas e européias demonstram como é difícil dissimular tais diferenças.

Além disso, a linguagem do empowerment, tão comumente empregada na retórica participativa, pode mascarar preocupações mais estreitamente relacionadas com a eficiência administrativa que tendem a retirar a conotação radical das reivindicações participativas dos anos 1960. Ao invés de formular ou veicular demandas radicais de transformação social ou de combate às desigualdades, alguns métodos participativos podem pôr em evidência técnicas pretensamente universais de desenvolvimento comunitário participativo. Como assinalam Cooke e Kothari (2001), o empoderamento seria para alguns gestores de projetos fórmula-chave para a solução de problemas (problem-solving), mas nunca ou pouco freqüentemente para a construção de problemas. 
A participação social, nesse caso particular, reduziria os custos e aumentaria a produtividade na prestação de serviços públicos descentralizados, porém não deveria estender-se no tempo, já que um processo longo (como podem ser os processos genuinamente participativos) seria considerado ineficiente e contraproducente. É claro que a ambigüidade temporal de muitas práticas participativas leva também a crer que, desde a simples difusão de informações sobre uma iniciativa de desenvolvimento local até a consulta ou a divisão de tarefas na implementação de um projeto, todas as etapas situadas nesse processo integrariam a "participação". Essa idéia de um continuum temporal da participação funcionaria como se não houvesse diferentes qualidades de participação nas distintas etapas de implementação de uma política pública local.

Finalmente, muitas técnicas participativas pregadas pela cooperação internacional colocam pessoas para trabalhar com a ajuda de um monitor ou mediador (um outsider, facilitador, consultor, animador ou agente da transformação) e pressupõem que o mero participar de um exercício participativo levaria necessariamente, no curto prazo, à transformação das consciências e à criação de laços de sociabilidade. Inúmeros cursos de treinamento promovidos por agências internacionais pressupõem, assim, que dezenas de pessoas, ao cabo de alguns dias de formação intensiva, teriam sido sensibilizadas e conscientizadas para a problemática dos direitos humanos, da democracia local, da educação preventiva, dos direitos sexuais e reprodutivos, da saúde familiar etc. Tais práticas ilustram perfeitamente o quão ingênuas podem ser as expectativas de alguns gestores de projetos no que diz respeito à autenticidade das motivações e dos comportamentos dos indivíduos no âmbito das chamadas oficinas participativas (participatory workshops). No caso de algumas das experiências aqui analisadas (Santo Domingo, Poitiers, Roma e Veneza), a função desempenhada pelos mediadores, sobretudo os mediadores externos aos municípios ou os consultores, tem o potencial de expressar esse tipo de risco.

\section{Conclusão: da manipulação política do princípio participativo à construção de ações públicas locais}

Pode-se reafirmar que a participação é parte integrante da realidade social na qual as relações sociais ainda não estão cristalizadas em estruturas. Sua ação é relacional; ela é construção da/na transformação social. As práticas participativas e suas bases sociais evoluem, variando de acordo com os contextos sociais, históricos e geográficos. No entanto, a análise das experiências aqui apresentadas demonstra que há elementos de continuidade independentemente dos 
contextos. Os atores locais (do governo à sociedade) têm função estratégica na renovação do processo de formulação de políticas públicas locais. A aplicação do princípio participativo pode contribuir na construção da legitimidade do governo local, promover uma cultura mais democrática, tornar as decisões e a gestão em matéria de políticas públicas mais eficazes (Ziccardi, 2004). Os governos locais, em particular, não são mais considerados simples agências prestadoras de serviços; são chamados a garantir a articulação do que Duran e Thoenig (1996) denominaram "ação pública local".

O desafio contemporâneo dos governos locais está, assim, diante da necessidade de produzir marcos propícios para o intercâmbio e a geração de acordos e denominadores comuns entre os atores do espaço local. Isso implica promover redes de atores sobre problemas públicos, ou seja, redes de política pública local. Implica também ter instrumentos de mobilização da cidadania; criar regras e arranjos institucionais que garantam previsibilidade, aumentem a confiança dos atores e diminuam as incertezas; implica ter uma capacidade estratégica para tecer acordos e articular convergências no momento oportuno; ou seja, ter a capacidade de gerar ações públicas de alta intensidade (Cabrero, 2004; Le Galès, 1998).

Ponto fundamental, a ação pública local não se refere somente à ação governamental, mas a uma ação coletiva em que atores governamentais e não-governamentais tomam parte de um processo político sobre um assunto de natureza pública. Uma rede de política pública é um exemplo claro de ação pública local; à medida que a ação pública tenha interfaces, ramificações e conexões mais densas, maior será a sua intensidade. O nível de intensidade da ação pública local depende do grau com que atores governamentais e nãogovernamentais atuam em torno de uma política pública específica (Duran e Thoenig, 1996; Cabrero, 2004).

Utilizando a categoria analítica de ação pública local, apresentamos uma representação gráfica que tenta situar as experiências analisadas neste artigo em função de dois critérios: o seu caráter deliberativo e o seu caráter de inclusão de atores locais. Quanto maior a densidade democrática da deliberação e a capacidade da experiência de incluir um leque diversificado de atores locais, maior a intensidade da ação pública local. ${ }^{9}$

\footnotetext{
9 É claro que a proposta de classificação das ações públicas locais, aqui apresentada, remete-nos à necessidade de ir muito além, no curso de nossas pesquisas, na análise qualitativa do posicionamento dos atores, seus discursos e suas práticas efetivas no âmbito dos dispositivos participativos.
} 


\section{As experiências como ação pública local}

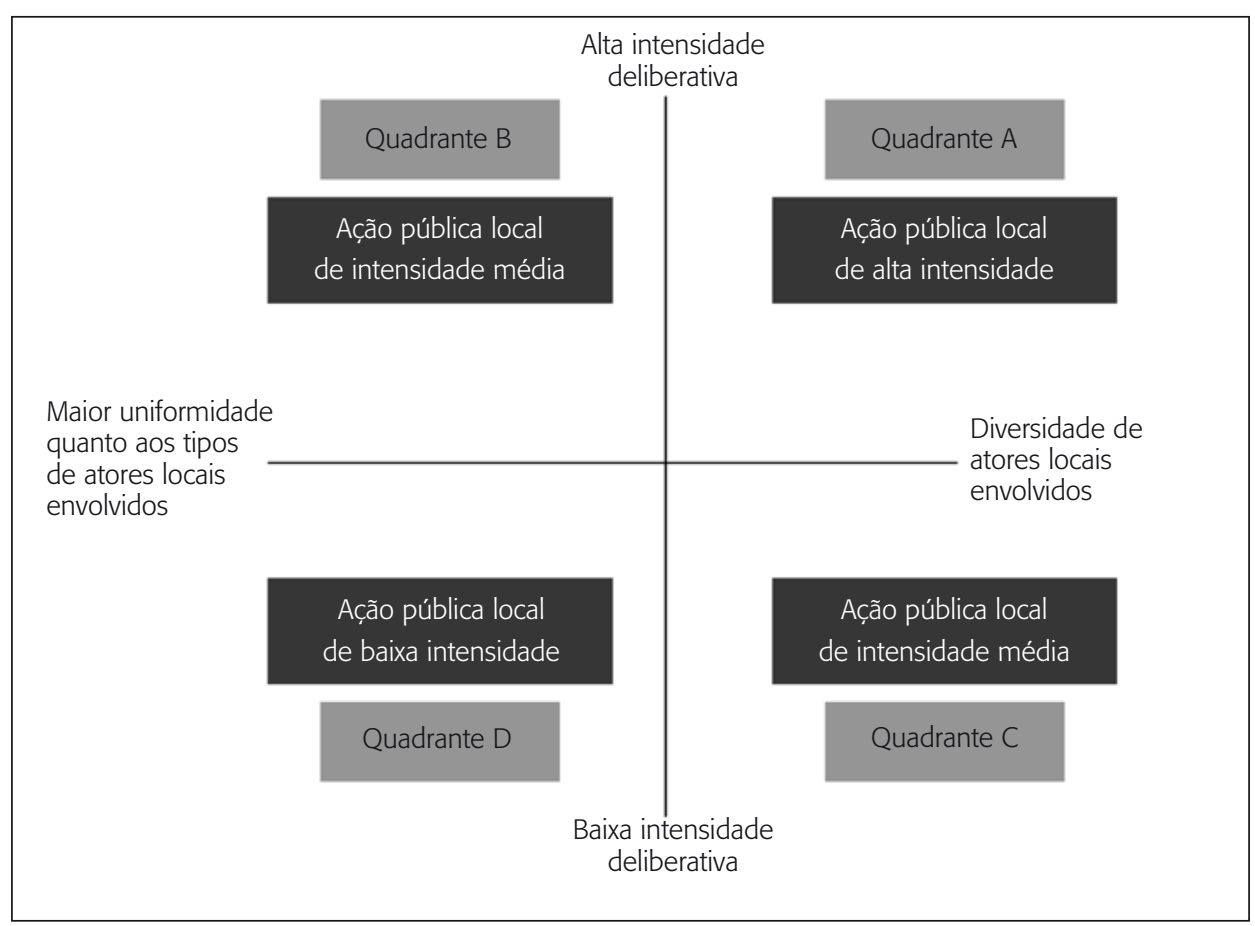

Fonte: Adaptado de Duran e Thoenig (1996) e Cabrero (2004).

No quadrante A, podem ser situadas as experiências de Belo Horizonte, Porto Alegre, Córdoba (Espanha), Veneza e Roma, que são todas de cunho deliberativo e incluem uma diversidade ampla de atores locais no processo decisório. ${ }^{10}$ No quadrante B, situam-se os casos de Santo Domingo (ausência, em função das características do contexto político, de autoridades representativas do Executivo local) e Poitiers (por ainda não incluir associações locais no processo decisório). No quadrante $\mathrm{C}$, incluem-se os casos de Córdoba (Argentina) e Asserí, onde o processo de participação cidadã não é de ordem deliberativa. No quadrante $\mathrm{D}$, finalmente, insere-se o caso de Hilden, que não é um pro-

${ }^{10}$ O OP de Porto Alegre, com a mudança de partido político no governo local (eleições de 2004), foi integrado ao Fórum da Governança Local e Solidária. Pelo menos até o momento, não houve modificações em sua estrutura de funcionamento. 
cesso deliberativo, não integra as associações locais e não atrai a população jovem do município (mais de 78,9\% dos participantes têm 50 anos ou mais).

Se um dos desafios maiores para a gestão pública local diz respeito à necessidade de democratizar os processos decisórios na formulação de políticas públicas e de torná-las mais efetivas, as ações públicas locais podem ser uma oportunidade sobretudo para as políticas sociais. Uma vez que estas se encontram, no âmbito nacional, sob a tutela de ajustes macroeconômicos, as soluções não encontradas no plano nacional podem ser pensadas criativamente, desenvolvidas e implementadas localmente. No entanto, as ações públicas locais não podem ser consideradas expressões efêmeras de um localismo mágico e estar fundadas exclusivamente na espontaneidade. Deve-se, outrossim, pensar a necessária complementaridade entre os diferentes níveis de ação política. Os governos locais podem desempenhar a função nodal no processo de articulação das redes de política pública, desde que, para desempenhar tal papel, tenham os recursos orçamentários e os meios políticos e institucionais necessários.

\section{Referências bibliográficas}

ALLEGRETTI, Giovanni. Participation in urban planning decision-making in Italy: new challenges for local authorities and citizens organisations. In: SEMINARIO INTERNACIONAL DERECHO Y ESPACIO URBANO, 9. Memorias... Quito: Cuaderno de Trabajo PGU/UN-Habitat/UNDP/Irglus, 2003.

AVRITZER, L. O orçamento participativo e a teoria democrática: um balanço crítico. In: ; NAVARRO, Zander (Orgs.). A inovação democrática no Brasil. São Paulo: Cortez, 2003. p. 13-60.

BEVORT, A. Pour une démocratie participative. Paris: Presses de Sciences-Po, La Bibliothèque du Citoyen, 2002.

BLATRIX, Cécile. Devoir débattre, les effets de l'institutionnalisation de la participation sur les formes d'action collective. Politix, v. 15, n. 57, p. 79-102, 2002.

BLONDIAUX, L.; SINTOMER, Yves. Limpératif délibératif. Politix, v. 15, n. 57, p. 17-35, 2002.

BRESSER-PEREIRA, Luiz Carlos; SPINK, Peter. Reforma do Estado e administração pública gerencial. São Paulo: FGV, 1998.

BURNELL, P. Foreign aid in a changing world. Londres: Open University Press, 1997. 
CABRERO, Enrique. Cogestión gobierno-ciudadanía en programas de bienestar social en el espacio municipal. Un balance preliminar. In: ZICCARDI, Alicia (Org.). Participación ciudadana y políticas sociales del âmbito local. México (DF): IIS/Comecso/Indesol, 2004.

COOKE, Bill; KOTHARI, Uma. Participation: the new tirany. New York: Zed Books (USA), 2001.

CUNILL GRAU, Nuria. Balance de la participación ciudadana em lãs políticas sociales. Propuesta de um marco analítico. In: ZICCARDI, Alicia (Org.). Participación ciudadana y políticas sociales del âmbito local. México (DF): IIS/Comecso/Indesol, 2004.

DAGNINO, E. Sociedade civil, espaços públicos e a construção democrática no Brasil: limites e possibilidades. In: Paulo: Paz e Terra, 2002. p. 279-301. . Sociedade civil e espaços públicos no Brasil. São

DAHL, Robert. Sobre a democracia. Brasília: UnB, 2001.

DRAIBE, Sônia Miriam. Por um novo contrato social como base para o enfrentamento da pobreza. In: CASTRO, Ana Célia (Org.). Desenvolvimento em debate: novos rumos do desenvolvimento no mundo. Rio de Janeiro: Mauad/BNDES, 2002. p. 265-273.

DURAN, P; THOENIG, J. C. LEtat et la gestion publique territoriale. Revue Française de Science Politique, v. 46, n. 4, 1996.

ECHEVARRÍA, Corina. O povo: assiste ao jogo ou joga? Reflexões em torno do espaço público nas instituições de gestão participativa. In: ENCONTRO NACIONAL DA ANPUR, 11. Anais... Salvador, 2005.

ELSTER, J. (Org.). Deliberative democracy. Cambridge: Cambridge University Press, 1998.

ESCOBAR, A. Encountering development: the making and unmaking of the third world. Princeton: Princeton University Press, 1994.

FEDOZZI, Luciano. O poder da aldeia: gênese e história do orçamento participativo de Porto Alegre. Porto Alegre: Tomo Editorial, 2000.

FISHKIN, J. Democracy and deliberation. New Haven: Yale University Press, 1991. FONT, Joan (Org.). Ciudadanos y decisiones públicas. Barcelona: Editorial Ariel, 2001.

FUKS, Mario; PERISSINOTTO, Renato. Recursos, decisão e poder, conselhos gestores de políticas públicas de Curitiba. Revista Brasileira de Ciências Sociais, v. 21, n. 60 , p. 67-81, fev. 2006. 
GALLICCHIO, Emrique; CAMEJO, Alejandra. Desarrollo local y descentralización en América Latina. Montevideo: Claeh, 2005.

GRINDLE, Marilee S. Audacious reforms: institutional reform and democracy in Latin America. Baltimore: Johns Hopkins University Press, 1999.

GUIJT, I.; SHAH, M. Kaul. The myth of community: gender issues in participatory development. Londres: Intermediate Technology Publications, 1998.

HABERMAS, J. L'Espace public, archéologie de la publicité comme dimension constitutive de la société bourgeoise. [1978]. Paris: Payot, 1990.

KOOIMAN, Jan. Modern governance, new government-society interactions. Londres: Sage Publications, 1993.

LAVALLE, Adrián Gurza; HOUTZAGER, Peter P; CASTELLO, Graziela. Representação política e organizações civis, novas instâncias de mediação e os desafios da legitimidade. Revista Brasileira de Ciências Sociais, v. 21, n. 60, p. 43-66, fev. 2006.

LEAL, Suely. Fetiche da participação popular: novas práticas de planejamento, gestão e governança democrática no Recife. Recife: Ed. do Autor, 2003.

LE GALES, Patrick. Les politiques locales et la recomposition de l'action publique. In: BALME, Richard et al. (Orgs.). Politiques locales et transformations de l'action publique en Europe. Grenoble: Cerat/AFSP, 1998. p. 101-114.

MANIN, B. Lidée de démocratie délibérative dans la science politique contemporaine. Politix, v. 15, n. 57, p. 37-55, 2002.

MARQUETTI, A. Participação e redistribuição: o orçamento participativo de Porto Alegre. In: AVRITZER, L.; NAVARRO, Zander (Orgs.). A inovação democrática no Brasil. São Paulo: Cortez, 2003. p. 129-156.

MILANI, Carlos. Como articular o "capital" e o "social"? Teorias sobre o capital social e implicações para o desenvolvimento local. Santa Cruz do Sul: Unisc, Redes, v. 9, n. 2, p. 31-54, 2004.

; KERAGHEL, Chloé. The international agenda for sustainable development: what position is there for international contestatory movements? In: THOYER, S.; MARTIMORT-ASSO, B. Participation for sustainability in trade. Londres: Zed Books, 2005.

NAVARRO, Zander. O orçamento participativo de Porto Alegre (1989-2002): um conciso comentário crítico. In: AVRITZER, L.; NAVARRO, Lander (Orgs.). A inovação democrática no Brasil. São Paulo: Cortez, 2003. p. 89-128.

OLIVEIRA, Francisco de. Aproximações ao enigma: que quer dizer desenvolvimento local? In: SPINK, Peter et al. (Orgs.). Novos contornos da gestão local: conceitos em 
construção. São Paulo: Polis; Programa Gestão Pública e Cidadania/FGV-Eaesp, 2002.

PADDISON, Ronan. Decoding decentralization, the marketting of local urban power? Urban Studies, v. 36, n. 1, p. 107-119, 1999.

RAUBER, Isabel. Construyendo poder desde abajo. Debate popular. Santo Domingo, 1994. co, 2000.

et al. Género y pobreza. Santo Domingo: Pasado y Presente XXI-Most-Unes-

RIBEIRO, Ana Clara Torres; GRAZIA, Grazia de. Experiências de orçamento participativo no Brasil (período de 1997 a 2000). Petrópolis: Vozes, Fórum Nacional de Participação Popular, 2003.

ROJO, Raúl; MILANI, Carlos; ARTURI, Carlos. Expressions of political contestation and mechanisms of democratic control. International Social Science Journal, Londres: Blackwell/Unesco, n. 182, p. 615-628, 2004.

SOUZA, Celina. A nova gestão pública. In: Gestão pública: desafios e perspectivas. Salvador: Fundação Luís Eduardo Magalhães, 2001. p. 38-62., 2001.

SUBIRATS, Joan. Nuevos mecanismos participativos y democracia: promesas y amenazas. In: FONT, Joan (Org.). Ciudadanos y decisiones públicas. Barcelona: Editorial Ariel, 2001. p. 33-42.

TEIXEIRA, E. O local e o global: limites e desafios da participação cidadã. São Paulo: Cortez; Salvador: UFBA; Recife: Equip, 2001.

UNDP. Human Development Report. New York e Oxford: Oxford University Press, 1993.

ZICCARDI, Alicia. Espacios e instrumentos de participación ciudadana para lãs políticas sociales del âmbito local. In:

(Org.). Participación ciudadana y políticas sociales del âmbito local. México (DF): IIS/Comecso/Indesol, 2004. 